\title{
A MODEL OF URBAN FOREST SUSTAINABILITY: APPLICATION TO CITIES IN THE UNITED STATES
}

\author{
by James R. Clark and Nelda P. Matheny
}

\begin{abstract}
The applicability of a model for urban forest sustainability was evaluated through a written survey. The model considers the character of the vegetation resource, community awareness of, and attitudes about, urban forests, and the management programs for the resource. Results from 25 U.S. cities were evaluated using the 20 criteria and four levels of performance found in the model. Although surveys were sent directly to mayors, urban forestry professionals completed the questionnaires. The average score for responding cities was 48.8 , out of a maximum score of 80 . The range in scores was 27 to 61 . Criteria of sustainability with highest overall scores dealt with awareness of trees as a community resource and neighborhood action; the lowest scores involved the participation of private landholders in urban forest management and regional cooperation.
\end{abstract}

Creation and management of urban forests to achieve sustainability is the long-term goal of urban foresters as well as elected officials, business leaders, and citizens. Clark et al. (1997) previously described a model for assessing a community's progress towards this goal. In their model, a sustainable urban forest was defined as "the naturally occurring and planted trees in cities which are managed to provide the inhabitants with a continuing level of economic, social, environmental and ecological benefits today and into the future." The model considers three broad categories:

- Vegetation Resource: knowledge of the existing tree resource

- Community Framework: interaction and cooperation of constituent groups

- Resource Management: current management programs

To assess progress towards a sustainable urban forest, communities must have criteria to measure the current state of these three components. Historically, any such criteria have been qualitative in nature and lacked universal applicability. In the 1996 State of the Urban Forest Report (Sacramento Urban Forest Task Force
1996) for the Sacramento region, sustainability was assessed qualitatively, through 16 regionally specific criteria. In an approach focused on municipal programs, Thompson et al. (1994) identified four criteria of sustainable urban forests with a variety of qualitative assessment measures. In contrast to these examples, the model developed by Clark et al. provided a method of assessment that was region-independent and quantitatively based (Table 1). This paper presents an evaluation of the applicability of this model based upon the results of a survey of cities across the United States.

\section{Methods and Materials}

A written survey was developed that adapted the criteria of sustainability and performance indicators identified by Clark et al. (1997) into a series of open- and close-ended questions. In the openended questions, respondents were asked to provide opinions, examples, and experiences. In the close-ended questions, the possible responses corresponded directly to the four levels of performance suggested for each criteria of sustainability. For example, one of the criteria in the Community Framework component is the interaction among citizen, government, and business groups. The performance indicators of this criterion are as follows:

- Optimal: formal interaction (such as tree board with staff coordination)

- High: informal and/or general cooperation

- Moderate: no interaction among constituencies

- Low: conflicting goals among constituencies

In the survey, the question corresponding to this criterion was, "What is the level of interaction among government, citizens, institutions, corporations, and other constituent groups?" 
Respondents could choose from among the following answers:

- Excellent, we have regular interaction (formal working group, city tree board, mayor's advisory committee, etc.).

- We have a tree board with communitywide representation, but it is not supported by city staff.
- Good, we have many informal contacts throughout the city.

- Fair, we have good interaction with some, conflicts with others.

- There is little interaction.

- Various groups are often in conflict.

Respondents were also asked, "Are there particular issues or topics that foster interaction

Table 1. Criteria for urban forest sustainability. Each criterion includes four levels of performance towards attaining the key objective (Clark et al. 1997).

\begin{tabular}{ll}
\hline Component & Criteria \\
Vegetation & Canopy cover \\
Resource & Age distribution of trees in community \\
& Species mix \\
& Native vegetation
\end{tabular}

Community

Framework

Resource

Management
Public agency cooperation

Involvement of large private and institutional landholders

Green industry cooperation

Neighborhood action

Citizen-government-business interaction

General awareness of trees as community resource

Regional cooperation

Citywide management

Citywide funding

City staffing

Assessment tools

Protection of existing trees

Species and site selection

Standards for tree care

Citizen safety

Recycling
Key objective

Achieve climate-appropriate degree of tree

canopy communitywide.

Provide for uneven age distribution.

Provide for species diversity.

Preserve and manage regional biodiversity.

Maintain the biological integrity of native remnant forests. Maintain wildlife corridors to and from the city.

Ensure all city departments operate with common goals and objectives.

Large private landholders embrace citywide goals and objectives through specific resource management plans.

The green industry operates with high professional standards and commits to citywide goals and objectives.

At the neighborhood level, citizens understand and participate in urban forest management.

All constituencies in the community interact for the benefit of the urban forest.

The general public understands the value of trees to the community.

Provide for cooperation and interaction among neighboring communities and regional groups.

Develop and implement a management plan for trees and forests on public and private property.

Develop and maintain adequate funding to implement a citywide management plan.

Employ and train adequate staff to implement citywide management plan.

Develop methods to collect information about the urban forest on a routine basis.

Conserve existing resources, planted and natural, to ensure maximum function.

Provide guidelines and specifications for species use, on a context-defined basis. Adopt and adhere to professional standards for tree care.

Maximize public safety with respect to trees. Create a closed system for tree waste. 
among groups? that inhibit interaction among groups?"

Forty-five cities in the United States were identified as potential participants in the survey. Participant cities were selected based upon the following criteria:

- population between 30,000 and 750,000 (Chicago, Illinois, was an exception)

- geographic diversity, including natural forest diversity

- membership in U.S. Conference of Mayors

- active involvement with the programs of the Trust for Public Land

- existing municipal urban forestry program or nonprofit group

Surveys were sent directly to the mayor of each city, with a cover letter from the Conference of Mayors. Communities that did not return surveys within the designated completion period were contacted and encouraged to complete the survey.

Survey responses were converted to numerical scores based upon specific indicators of performance (i.e., no or negative response $=0$, low $=1$, fair $=2$, high $=3$, optimal $=4$ ). Half-units (e.g., 2.5) were used in some cases. For example, in the question dealing with interaction among constituent groups scores were assigned as follows:

\section{Response}

Score

Excellent, we have regular interaction...

We have a tree board with communitywide representation...

Good ...

3.5

Fair ...

There is little interaction

Groups are in conflict

Numerical scores were equally weighted and summarized for each of the 20 criteria in the sustainability model, yielding a maximum possible score of $\mathbf{8 0}$. Results were summarized in spreadsheet format then imported into Statview, a statistical analysis program.

\section{Results}

Twenty-five cities returned completed surveys, a response rate of $56 \%$ (Table 2 ). The geographic distribution of responding cities ranged across the
Table 2. Population and size of responding cities.

\begin{tabular}{lrr}
\hline City & \multicolumn{1}{c}{$\begin{array}{c}\text { Population } \\
(1990)\end{array}$} & \multicolumn{1}{c}{$\begin{array}{c}\text { Area } \\
\text { (ha) }\end{array}$} \\
\hline Livermore, CA & 56,741 & 5,076 \\
Modesto, CA & 180,000 & 8,761 \\
San Francisco, CA & 700,000 & 12,691 \\
Colorado Springs, CO & 281,140 & 35,224 \\
Denver, CO & 467,610 & 40,049 \\
Atlanta, GA & 415,200 & 34,188 \\
Chicago, IL & $3,719,000$ & 59,173 \\
Fort Wayne, IN & 180,000 & - \\
Topeka, KS & 119,883 & 14,426 \\
Louisville, KY & 269,063 & 15,540 \\
Baton Rouge, LA & 380,105 & 122,248 \\
Lowell, MA & 104,000 & - \\
Baltimore, MD & 750,000 & 22,533 \\
Cincinnati, OH & 365,000 & 19,425 \\
Cleveland, OH & 505,616 & 19,943 \\
Providence, RI & 160,000 & - \\
Charleston, SC & 80,414 & 11,370 \\
Rock Hill, SC & 41,643 & 6,195 \\
Sioux Falls, SD & 100,814 & 11,655 \\
Ft. Worth, TX & 447,619 & 76,455 \\
Mesquite, TX & 101,484 & 10,878 \\
Salt Lake City, UT & 160,000 & 27,972 \\
Seattle, WA & 516,259 & 23,828 \\
Milwaukee, WI & 628,088 & 24,812 \\
Cheyenne, WY & 50,008 & 4,403 \\
\hline & &
\end{tabular}

continental United States. City population ranged from 41,643 (Rock Hill, South Carolina) to $3,719,000$ (Chicago, Illinois). The average population was 431,187 (median population was $269,063)$. The size of respondent cities ranged from 4,403 to 122,248 ha (17.0 to $\left.472 \mathrm{mi}^{2}\right)$ with an average area of 27,454 hectares $\left(106 \mathrm{mi}^{2}\right)$.

Although the surveys were addressed to the individual mayors in each city, for the most part they were completed by professional staff members within city government. Job titles included urban forester, city forester, city arborist, park superintendent, landscape supervisor, natural resource manager, and director of landscape and forestry. In two cases (Chicago, Illinois, and Lowell, Massachusetts), surveys were completed by program directors (Chicago: Greenstreets; Lowell: Parks and Conservation Trust). For some cities, more than one person took part in completing the survey.

The average score for the respondent cities was 48.8, with a range from 27 to 61 (maximum possible score of 80 ) (Figure 1; Table 3 and Table 


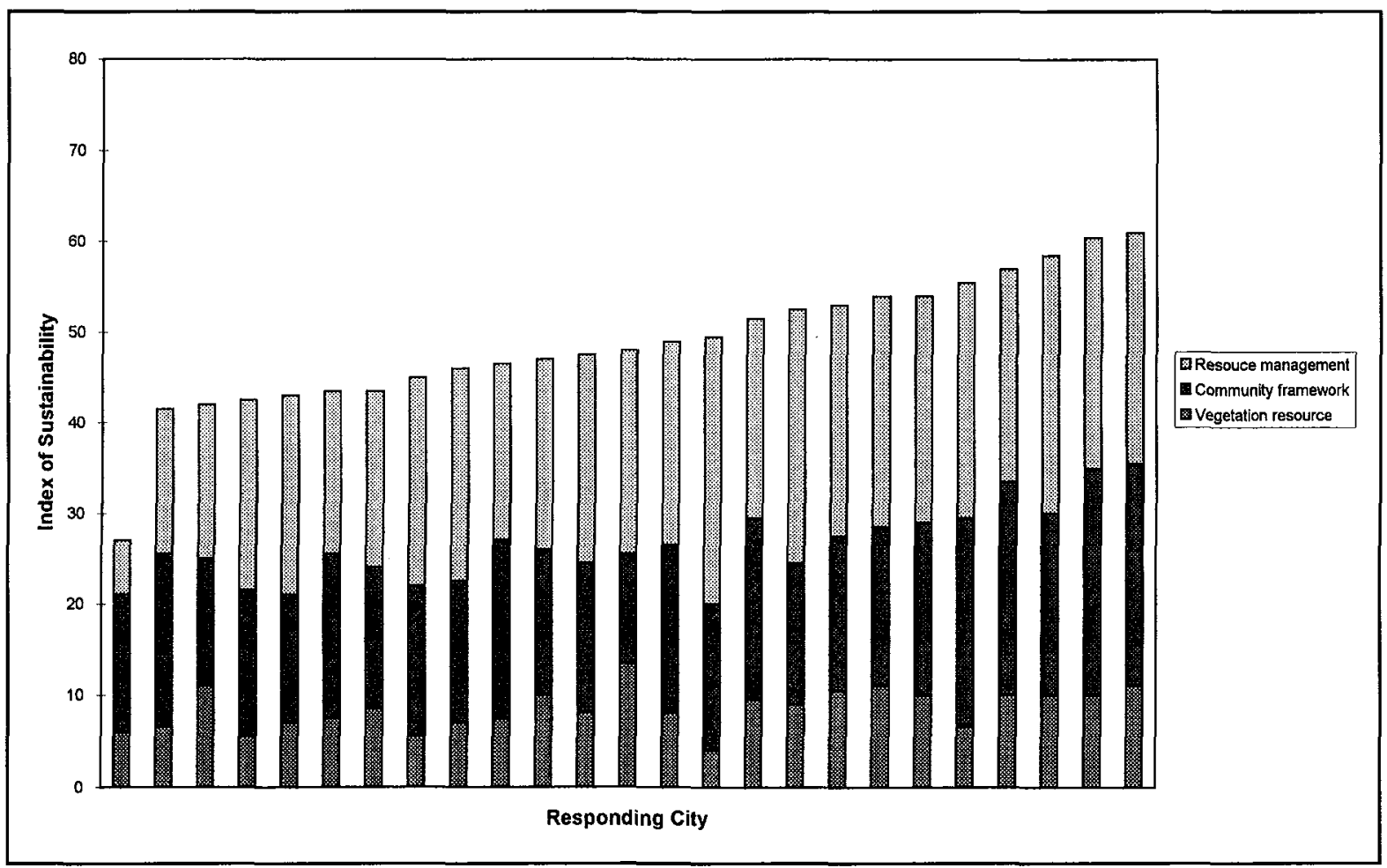

Figure 1. Compiled urban forest sustainability model scores of responding cities.

4). A wide range in scores existed among the three components of the sustainability model. For the vegetation resource component, the average value was 8 , with a range of 4 to 13.5 (maximum possible score: 16). For the community framework component, the average score was 17.9 , with a range of 12 to 25 (maximum score: 28 ). The range in scores for the resource management component was 6 to 29, with an average of 22.4 (maximum score: 36 ). No significant relationship was found between overall score and city population or size. Both high and low scores were obtained by large and small cities.

The average numerical score for all 20 criteria in the sustainability model for all respondent cities was $2.43\left(\mathrm{SE}_{\text {mean }} 0.04\right)$. The range in scores was 1.78 to 3.06 (maximum score: 4) (Figure 2; Table 5). The two lowest-scoring criteria were both in the Community Framework component. One dealt with the involvement of holders of large private and institutional lands in management of the urban forest, with a score of 1.78 . Only 13 cities had information about this constituent group. The sec- ond low-scoring question involved regional cooperation among communities, with a score of 1.98 .

The highest-scoring criteria were also in the Community Framework component. The criterion dealing with community awareness of trees and urban forests had an average score of 3.06. Other high-scoring criteria were neighborhood action in urban forest planning and management (2.96), cooperation among green industry groups (2.88), capacity of city staff to implement a citywide management plan (2.88), and the use of tree care standards as a management tool (2.86).

Responses to the open-ended questions reflected the views of municipal urban forestry/ arboriculture staff on a variety of topics. For example, several questions considered the role of constituent groups in urban forest management (Table 6 and Table 7). Staff completing the surveys viewed city government and community groups as the most important constituent groups (Table 6). In contrast, business districts, corporations, and private landholders were seen as less important and not critical. In two cases, respon- 
dents viewed city government and the general public as a liability to urban forest management.

Respondents to the survey also commented on the importance that various city departments place on the urban forest (Table 7). The most positive comments were made about forestry and parks units. In contrast, $20 \%$ to $25 \%$ of the respondents viewed the public utility and public works units in a negative way (e.g., "These departments view trees and urban forests as a liability").

Community groups were considered either important or vital to the management of public trees (Table 8). None of the responding cities regarded community groups in a negative manner. Contributions made by such groups included general awareness of the need for management, a source of direct labor, and financial support. Issues to which community groups responded in a positive manner included tree planting and the environmental benefits provided by trees. Issues evoking negative attitudes included uplifted sidewalks, litter, and interference with signs and lights.

Respondents provided detailed information about their city's urban forest resource. Sixty percent of respondents knew the number of trees on streets; $20 \%$ knew the number of park trees. However, only one respondent knew the number of trees in the entire city (public and private land). Sixty-four percent of respondents knew the extent of canopy cover across their community and $40 \%$ had specific target goals for the amount of cover.

For cities with urban forest management plans (64\% of respondents), such plans were largely restricted to public trees. Only one city (Sioux Falls, South Dakota) had an urban forest management plan that considered all trees in the community, both public and private.

Existing urban forest management included use of a number of tools for assessing tree species, age, condition, and location (Table 9). Resource information was incorporated into geographic information systems (GIS) in $40 \%$ of surveyed communities. Other assessment tools cited by respondents included inventories, aerial photographs, and windshield surveys. Use of comprehensive assessment tools was clearly reflected in the scores for the Vegetation Re-
Table 3. Summary of survey results for the model of urban forest sustainability.

\begin{tabular}{|c|c|c|c|c|}
\hline \multirow[b]{2}{*}{ Component } & \multirow{2}{*}{$\begin{array}{l}\text { Maximum } \\
\text { score }\end{array}$} & \multicolumn{2}{|c|}{ Range } & \multirow[b]{2}{*}{ Average } \\
\hline & & low & high & \\
\hline $\begin{array}{l}\text { Vegetation } \\
\text { Resource }\end{array}$ & 16 & 4 & 13.5 & 8.5 \\
\hline $\begin{array}{l}\text { Community } \\
\text { Framework }\end{array}$ & 28 & 12 & 25 & 17.9 \\
\hline $\begin{array}{l}\text { Resource } \\
\text { Management }\end{array}$ & 36 & 6 & 29 & 22.4 \\
\hline Overall & 80 & 27 & 61 & 48.8 \\
\hline
\end{tabular}

Table 4. Urban forest sustainability model scores for responding cities.

\begin{tabular}{lrrrr}
\hline & \multicolumn{3}{c}{ Score } & \\
\cline { 2 - 4 } City & Veg. & Comm. & Res. & \\
No. & Res. & Frame. & Mgt. & Total \\
\hline 1 & 6 & 15 & 6 & 27 \\
2 & 6.5 & 19 & 16 & 41.5 \\
3 & 11 & 14 & 17 & 42 \\
4 & 5.5 & 16 & 21 & 42.5 \\
5 & 7 & 14 & 22 & 43 \\
6 & 7.5 & 18 & 18 & 43.5 \\
7 & 8.5 & 15.5 & 19.5 & 43.5 \\
8 & 5.5 & 16.5 & 23 & 45 \\
9 & 7 & 15.5 & 23.5 & 46 \\
10 & 7.5 & 19.5 & 19.5 & 46.5 \\
11 & 10 & 16 & 21 & 47 \\
12 & 8 & 16.5 & 23 & 47.5 \\
13 & 13.5 & 12 & 22.5 & 48 \\
14 & 8 & 18.5 & 22.5 & 49 \\
15 & 4 & 16 & 29.5 & 49.5 \\
16 & 9.5 & 20 & 22 & 51.5 \\
17 & 9 & 15.5 & 28 & 52.5 \\
18 & 10.5 & 17 & 25.5 & 53 \\
19 & 11 & 17.5 & 25.5 & 54 \\
20 & 10 & 19 & 25 & 54 \\
21 & 6.5 & 23 & 26 & 55.5 \\
22 & 10 & 23.5 & 23.5 & 57 \\
23 & 10 & 20 & 28.5 & 58.5 \\
24 & 10 & 25 & 25.5 & 60.5 \\
25 & 11 & 24.5 & 25.5 & 61 \\
\hline & & & &
\end{tabular}

source category. Communities that were aware of the species mix had knowledge of the age distribution as well.

\section{Discussion}

The survey was designed to evaluate the utility of the model developed by Clark et al. (1997) in assessing the sustainability of urban forests. To that end, the survey asked both closed- and open ended questions about each criterion and per- 


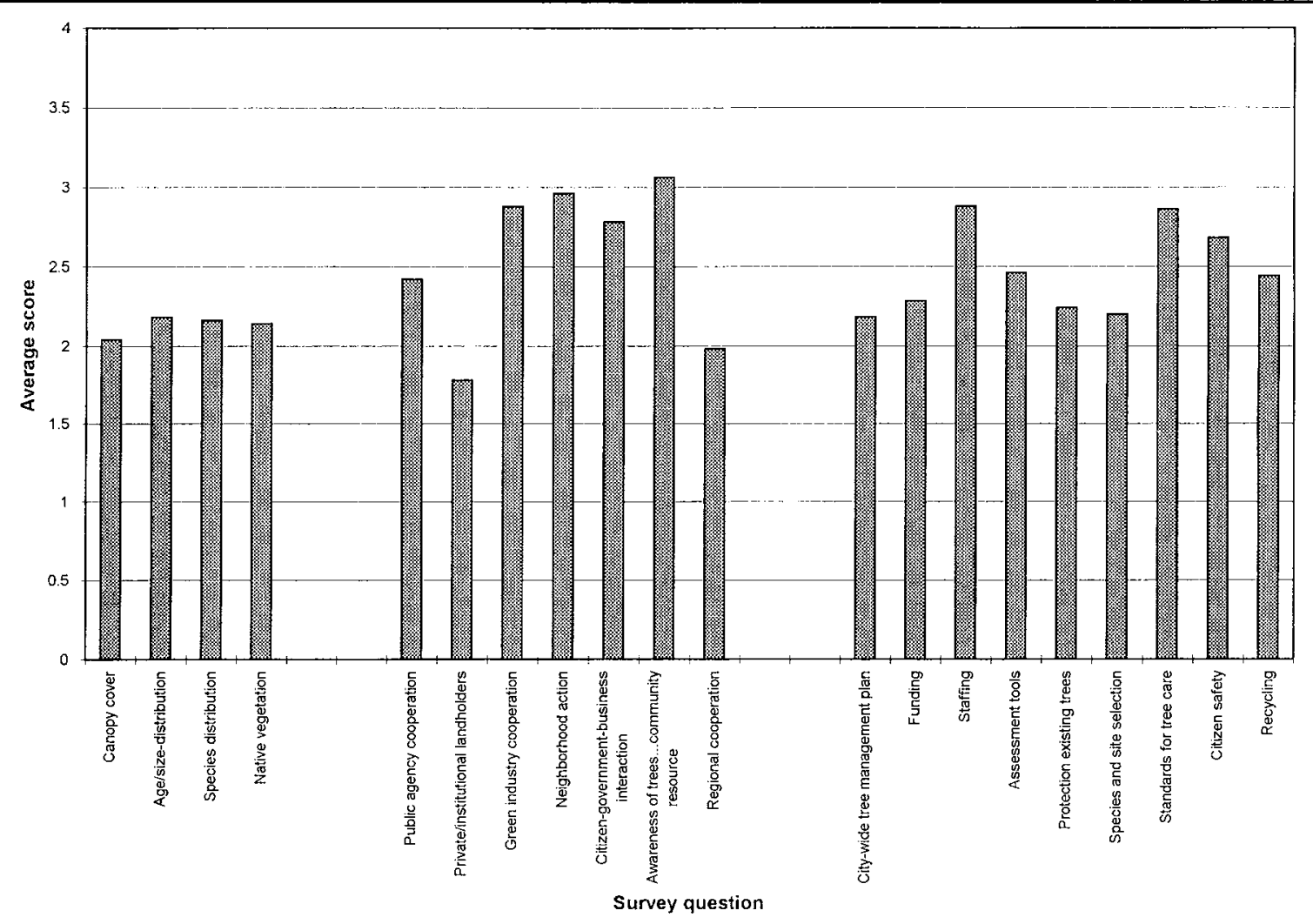

Figure 2. Compiled scores to urban forest sustainability model survey questions.

formance indicator contained in the model. By assigning a numerical rating to each performance indicator, researchers could compute for each city a summary score associated with progress towards a sustainable urban forest. In this way, a quantitative assessment of sustainability could be developed.

Under the model developed by Clark et al., a score of 80 represents a sustainable urban forest. Among the responding cities, the average score was 48.8, with a range from 27 to 61 (Table 4 and Figure 1). The model divides 20 criteria into three categories. The average score (as a percentage of the maximum) for each of these components was Vegetation Resource, 53\%; Community Framework, 64\%; and Resource Management, $62 \%$

Results for each city among the three categories were not uniform. There was wide variation among components-communities with high scores in one of the components did not necessarily have high scores in the others. For example, the community with the lowest score (4 of a possible 16) in the Vegetation Resource component had the highest score (29 of 36) in the Resource Management component.

Scores obtained from this survey reflect two of the important concepts of the sustainability model: 1) sustainable urban forests require human intervention and 2) trees growing on private lands comprise the majority of urban forests (Clark et al. 1997). For the first concept, the model includes the active interaction and participation of government, businesses, citizens, and other constituent groups. Because urban forests are a mix of naturally occurring and planted trees in specific locations, their creation and preservation require active planning and management by a diverse group of owners, managers, and stakeholders. 
Integrating management of private forests and lands into a citywide plan is a significant challenge to communities. For many of the model's performance indicators, the difference between a score of 2 and 3 is based upon consideration of trees on private lands. Unfortunately, few cities are aware of management efforts on private lands, let alone actively interact with those managers. A broadening of focus to consider all trees in the city must occur in order to achieve substantial progress towards sustainability. More actively involving private landholders in cooperative management programs and goals requires new thinking and approaches other than those historically employed with individual citizens. This does not mean that public agencies should oversee, direct, or otherwise regulate management of trees on private lands. Rather, there is a need for shared vision and agreement on goals, objectives, and management approaches.

Another aspect of broadening the focus is regional cooperation in urban forest management. Most of the respondents noted their involvement

Table 5. Scores for urban forest sustainability model criteria.

\begin{tabular}{lcc}
\hline $\begin{array}{l}\text { Model components } \\
\text { and criteria }\end{array}$ & Mean & $\begin{array}{r}\text { Standard } \\
\text { error }\end{array}$ \\
\hline $\begin{array}{l}\text { Vegetation Resource } \\
\text { Canopy cover }\end{array}$ & 2.04 & 0.18 \\
Age/size distribution & 2.18 & 0.16 \\
Species distribution & 2.16 & 0.14 \\
Native vegetation & 2.14 & 0.19 \\
Community Framework & & \\
Public agency cooperation & 2.42 & 0.12 \\
Private/institutional landholders & 1.78 & 0.20 \\
Green industry cooperation & 2.88 & 0.13 \\
Neighborhood action & 2.96 & 0.14 \\
Citizen-government-business & 2.78 & 0.16 \\
$\quad$ interaction & & \\
Awareness of trees as a & 3.06 & 0.18 \\
$\quad$ community resource & & \\
Regional cooperation & 1.98 & 0.14 \\
Resource Management & & \\
Citywide tree management plan & 2.18 & 0.15 \\
Funding & 2.28 & 0.19 \\
Staffing & 2.88 & 0.16 \\
Assessment tools & 2.46 & 0.15 \\
Protection existing trees & 2.24 & 0.19 \\
Species and site selection & 2.20 & 0.16 \\
Standards for tree care & 2.86 & 0.16 \\
Citizen safety & 2.68 & 0.21 \\
Recycling & 2.44 & 0.19 \\
\hline
\end{tabular}

in such professional organizations as the International Society of Arboriculture as examples of such cooperation. The model, however, considers regional cooperation to be the positive interaction of neighboring communities in urban forest management. This could take the form of consistency in tree preservation and resource conservation policies, pest management programs, or storm water runoff. The recently completed Chicago Urban Forest Ecosystem Project (McPherson et al. 1994) and Sacramento Urban Forest Ecosystem Study are examples of the potential to develop and implement regionally based resource assessment and management programs. Another example of the potential for regional cooperation involves the integration of riparian forests into urban storm drainage systems (Ellis 1995).

When we evaluated the survey results, several limitations of the sustainability model and survey approach became clear. First and foremost, the sustainability score represents the views of the respondent (i.e., the person completing the survey) resulting in a strong bias on at least two levels. The first bias of the respondent involves his or her perceptions and attitudes about the sustainability model. While we might hope that the municipal arborist or urban forester who completed these surveys represented the broader community views about a topic, there is no way to ensure this fact. The second respondent bias involves the cities and their elected officials. Surveys were sent to the mayor of each community, who then transferred it to the respondent. That this transfer occurred represents a positive interest in the urban forest.

Table 6. Constituent groups important to urban forest sustainability.

\begin{tabular}{lrrrc}
\hline & \multicolumn{3}{c}{ Importance of constituent groups to urban forest } \\
\cline { 2 - 5 } & $\begin{array}{r}\text { Absolutely } \\
\text { vital }\end{array}$ & Important & $\begin{array}{c}\text { Nice but } \\
\text { not critical }\end{array}$ & $\begin{array}{c}\text { No. of re- } \\
\text { sponses }\end{array}$ \\
Group & 18 & 6 & 1 & 25 \\
\hline City government & 12 & 9 & 3 & 24 \\
Community groups & 9 & 12 & 1 & 22 \\
Public & 9 & 14 & 3 & 22 \\
Green industry & 5 & 7 & 12 & 22 \\
Business districts & 3 & 10 & 11 & 22 \\
Corporations & 1 & 8 & 10 & 20 \\
Private landholders & 2 & & &
\end{tabular}


Another limitation of the survey involves privately owned trees. The sustainability model considers all trees within a community. The more information a city possesses about all trees in its communities, the higher its score. In some cases, the survey was completed by a team of staff members from such departments as parks, streets, and forestry. Scores from these communities are likely to be higher than those from cities for which the survey was completed by a single staff member whose responsibility involved only parks or only streets.

Finally, several of the model's criteria involve preservation of existing trees, particularly in native forests. Although it was not intentional, cities without a native forest resource were undoubtedly penalized in their overall score. We minimized this penalty by averaging scores for other criteria within the component group and applying the average to the questions dealing with a native forest resource.

We caution that the results obtained from this survey are not representative of the municipal urban forestry programs nationwide, for several reasons. First, we did not sample communities at random. Rather, we included cities about which we had prior knowledge of their urban forestry program or government structure. On this basis, the participant cities would be expected to score higher than those from a randomly selected

Table 7. Attitudes of city departments about the urban forest (as perceived by the respondents).

\begin{tabular}{lrrrrr}
\hline & \multicolumn{3}{c}{ Attitude about the urban forest } & \\
\cline { 2 - 4 } Department & Excellent $^{\mathrm{a}}$ & Fair $^{\mathrm{b}}$ & Poor $^{\mathrm{c}}$ & Responses \\
\hline Public utility & 6 & 14 & 5 & 25 \\
Parks & 17 & 7 & - & 24 \\
School district & 6 & 17 & 1 & 24 \\
Forestry & 22 & - & - & 22 \\
Planning & 14 & 8 & - & 22 \\
Boards and & 14 & 7 & - & 21 \\
$\quad$ commissions & & & & & \\
Public works & 5 & 11 & 5 & 21 \\
$\begin{array}{l}\text { Public housing } \\
\text { Assessment }\end{array}$ & 4 & 9 & - & 13 \\
$\quad$ districts & 6 & 4 & - & 10 \\
\hline
\end{tabular}

\section{${ }^{\mathrm{a}}$ Trees are great}

'Neutral

'Trees are liability

${ }^{d}$ E.g., design review, tree board group. Second, respondents to the survey represent a positive self selection (i.e., only communities with positive feelings about urban forests took the time to complete the survey). This includes both urban forestry professionals and elected officials. For cities that responded to the survey, the mayor felt strongly enough about the issue to pass the request on to the appropriate staff.

While we believe the sustainability model can be a powerful tool to communities in assessing sustainability, results of the survey identified some limitations. For example, the model's criteria are equally weighted. Given the central importance of the tree resource in making an urban forest, this component area may warrant stronger weighting. We also recognize that a long, complicated survey is not the most efficient method of assessment and are investigating more concise, well-structured evaluation forms.

Table 8. Involvement of community groups in management of urban forests.

\begin{tabular}{lc}
\hline Topic & No. of responses \\
\hline Importance of community groups to management of public \\
trees & \\
Critical & 8 \\
Important & 10 \\
Neutral & 5 \\
Negative & 0 \\
Contributions of community groups to urban forest \\
Direct financial support & 6 \\
Indirect financial support & 7 \\
Direct labor & 11 \\
General awareness & 15 \\
Issues associated with positive citizen attitudes \\
Support/demand tree planting & 5 \\
Environmental benefits & 5 \\
(including energy conservation) & \\
General support & 3 \\
Neighborhood improvement & 3 \\
Articles/editorials in newspaper & 2 \\
Increased property values & 2 \\
Dislike large-scale removal & 2 \\
Other & 7 \\
Issues associated with negative citizen attitudes \\
Uplifted sidewalks & 7 \\
Litter (leaves, fruit); demand & 6 \\
removal, prevent planting & \\
Interfere with signs and lights & 4 \\
Homeowner responsibility for care & 2 \\
View pruning & 2 \\
Vandalism & 2 \\
Other & 7 \\
\hline
\end{tabular}


Table 9. Urban forest assessment tools used by responding cities.

\begin{tabular}{|c|c|c|c|c|}
\hline \multirow[b]{3}{*}{ Assessment tool } & \multicolumn{4}{|c|}{ Resource type } \\
\hline & \multicolumn{3}{|c|}{ Public trees } & \multirow{2}{*}{$\begin{array}{l}\text { Private } \\
\text { trees }\end{array}$} \\
\hline & street & park & other & \\
\hline $\begin{array}{l}\text { Geographic information } \\
\text { system }\end{array}$ & 10 & 10 & 1 & 3 \\
\hline Complete inventory & 9 & 6 & - & - \\
\hline Partial inventory & 11 & 11 & - & 1 \\
\hline $\begin{array}{l}\text { Mapping from aerial } \\
\text { photographs }\end{array}$ & 11 & 12 & 2 & 6 \\
\hline $\begin{array}{l}\text { Other (e.g., windshield } \\
\text { survey) }\end{array}$ & 10 & 7 & - & 2 \\
\hline
\end{tabular}

\section{Literature Cited}

Clark, J.R., N.P. Matheny, G. Cross, and V. Wake. 1997. A model of urban forest sustainability. J. Arboric. 23:17-30.

Ellis, J. 1995. Integrated approaches for achieving sustainable development of urban storm drainage. Water Sci. Technol. 32:1-6.

McPherson, E.G., D.J Nowak, and R.A Rowntree. 1994. Chicago's Urban Forest Ecosystem: Results of the Chicago Urban Forest Climate Project. USDA For. Serv. Northeast For. Exp. Sta. Gen. Tech. Rpt. NE-186. Radnor, PA. 201 pp.

Sacramento Urban Forest Task Force. 1996. State of the Urban Forest Report 1996. City of Sacramento/ Sacramento Tree Foundation. Sacramento, CA. $44 \mathrm{pp}$.

Thompson, R., N. Pillsbury, and R. Hanna. 1994. The elements of sustainability in urban forestry. Urban Forest Ecosystems Institute. Calif. Poly. St. Univ. San Luis Obispo, CA. 56 pp.
Acknowledgements. We are particularly indebted to the elected officials and staff of the cities who responded to the survey. The research presented in this paper would not have been possible without their contributions. Thanks also to Gordon Bradley and Genni Cross for their review and advice on creating the survey, to Tom McClimon and the U.S. Conference of Mayors for their help in distributing the surveys to the participant cities, to Judy Thrapp for her assistance in producing and compiling the surveys, to Joshua Summit for his invaluable guidance in analyzing survey data, and to Greg McPherson, Bob Miller, and an anonymous reviewer for their very helpful comments and suggestions. Funding for this project was provided by a grant from the National Urban and Community Forestry Advisory Council through the USDA Forest Service Urban and Community Forestry Challenge Cost-share Program (No. G-5-94-20-095).

HortScience, Inc.

P.O. Box 754

Pleasanton, CA 94566 